\title{
A participação de mulheres artistas na revista Ephemera
} The participation of women artists in the Ephemera magazine

\author{
ANDRÉIA PAULINA COSTA \\ Universidade Estadual de Campinas (UNICAMP) Campinas SP, Brasil
}

\section{RESUMO}

Esse artigo têm como intuito analisar a revista Ephemera produzida por Ulises Carión entre os anos de 1977 e 1978, sob uma perspectiva de gênero. Dentre os doze números editados pela revista, como se deu a participação das artistas e em que medida seus trabalhos contribuíram de forma exemplar para a proposta crítica e experimental do escopo editorial e quais as problematizações por elas levantadas.

\section{PALAVRAS - CHAVE}

Mulheres artistas, arte postal, gênero, publicações independentes.

\begin{abstract}
A B S T R A C T
This article has the intention to analyze the Ephemera magazine produced by Ulises Carion between the years 1977 and 1978 on a gender perspective. Among the twelve issues edited by the magazine, how did the participation of women artists take place and the extent to which their work contributed in an exemplary way to the critical and experimental proposal of the editorial scope and what were the issues raised by them.
\end{abstract}

\section{KE YWORDS}

Women artists, mail art, gender, independent publications. 


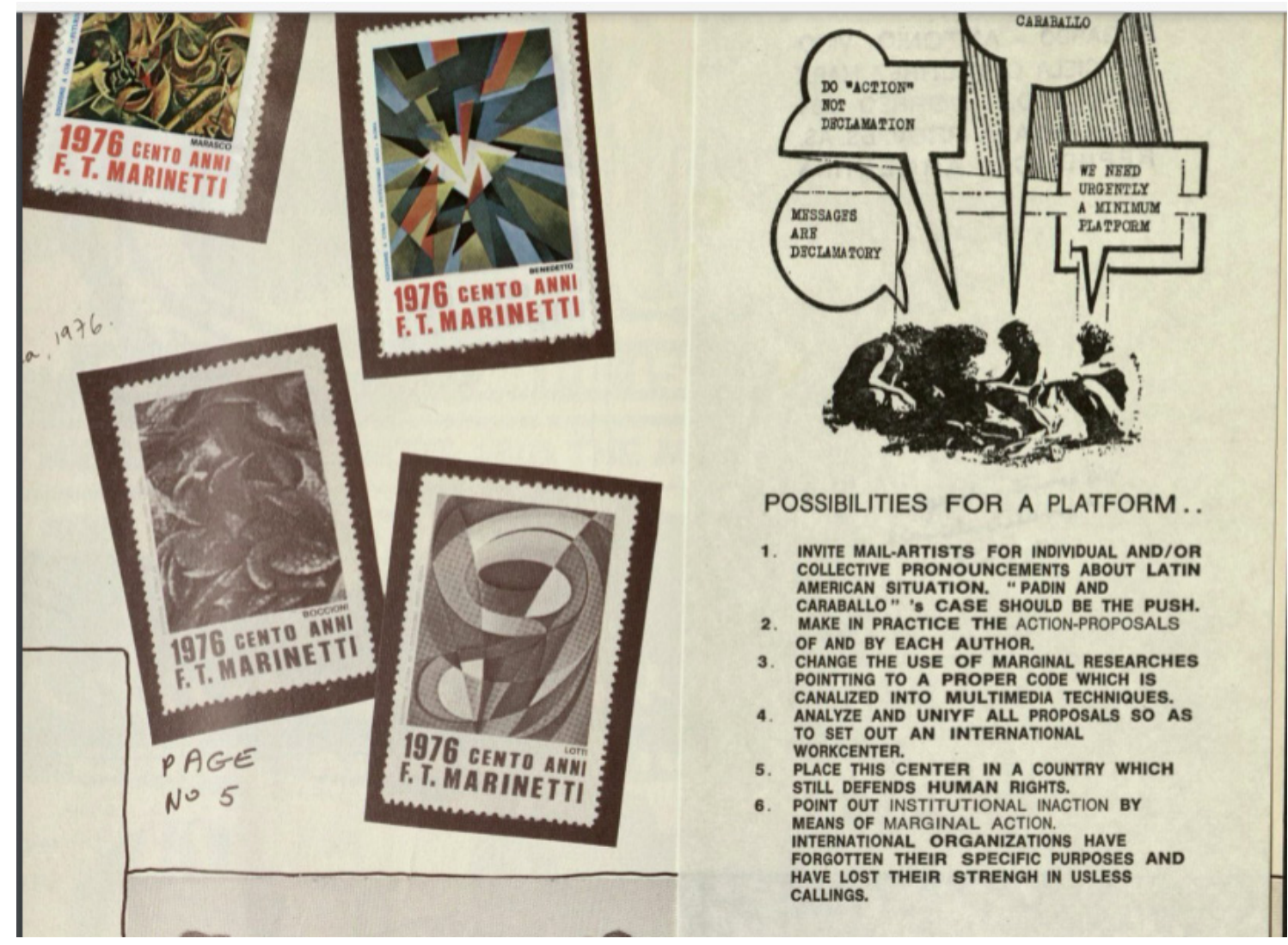

Figura1. - Ephemera ${ }^{\circ} 6$, Abril de 1978. Fonte: Monoskop 1

\section{Ephemera como projeto de experimentação editorial}

A revista Ephemera2, de caráter experimental e independente produzida entre 1977 e 1978 proposta pelos artistas Ulises Carrión, Aart van Barneveld - responsável pela revista postal Rubber Stamps - e Salvador Flores, circulou entre 1977 e 1978, publicada em 12 números pela editora-galeria de Ulises Carrión em Amsterdã, Other Books and So (1975-1979). De modo geral, o intuito da revista era disseminar os trabalhos recebidos via rede de arte postal. De acordo com Guy Schraenen (2016) as publicações da revista Ephemera "revelavam uma imensa diversidade de estéticas, concepções e trabalhos de origens geográficas distintas. Ao invés de expressar seu mundo pessoal, Carrión focou nas estratégias culturais” (SCHRAENEN, 2016³).

1 Para mais imagens e informações, todos os números da revista Ephemera, se encontram disponíveis online na página Monoskop.log.

2 As edições da revista Ephemera podem ser encontradas on-line na página Monoskop: https://monoskop. org/Ephemera. Acessado em 28/09/2020

3 Citação original: "revelando uma imensa diversidade na estética, na concepção e nas origens geográficas das obras. Em vez de expressar o seu próprio mundo pessoal, centra-se nas estratégias culturais. Quanto aos seus projetos de mail art, afirma que a totalidade das obras reunidas deve ser considerada como pertencente 
As estratégias culturais das quais Guy Schraenen fala, são aquelas já colocadas em funcionamento pela rede de artistas em colaboração que compõem a rede de arte postal: a troca de informações e a construção de estratégias de disseminação visual para além do sistema da arte internacional, em suas esferas de institucionalização e produção de discursos hegemônicos. Vale lembrar que nesse momento, entre final da década de 1960 até meados de 1980 os países do Cone Sul e do Leste da Europa vivenciavam uma forte repressão política por conta dos regimes ditatoriais atuantes no poder, marcando uma série de contraposições por parte dos artistas como o boicote à Bienal de São Paulo, organizada por Pierre Restany em 1969 e a produção da copilação ContraBienal em 1971, organizada por Luis Camnitzer e Liliana Porter, com auxílio de Gordon Matta-Clark para a promoção da extensão ao boicote à Bienal e, consequentemente, à repressão política (JAREMTCHUK, 20134), além da produção da Anti-Dokumenta em 1977.

Ao longo dos doze números da revista, o enfoque se deu sobretudo à publicação de trabalhos de artistas que circulavam em torno dessa rede postal, em sua maioria homens de diversos países. Isso nos coloca uma questão fundamental: apesar do campo da arte postal ter como núcleo um sistema disruptivo e democrático, à medida em que qualquer pessoa poderia enviar seus trabalhos, sendo ou não artista, consolidado ou não no sistema das artes, o número de mulheres artistas seja na revista Ephemera, seja como um todo ao longo dessa rede, é substancialmente menor, mas não por isso menos potente em termos de propostas críticas.

Um breve esboço sobre o conteúdo publicado nesses números nos aponta que os trabalhos eram em sua maioria no campo da fotografia, da poesia visual e da arte conceitual. A proposta central era a divulgação de produções que naquele momento de repressão e autoritarismo não tinham espaços de circulação, construindo uma rede de recepção, através de chamadas e publicações postais, que alcançaram diversos países como Japão, Austrália, Europa Ocidental, Américas e Leste da Europa, desenvolvendo uma descentralização no sistema das artes.

Vale salientar a $5^{a}$ edição da revista, na qual se torna claro o teor contestatório e subversivo. Em Agosto de 1977 Clemente Padin e Jorge Caraballo5 foram presos pela polícia uruguaia em Montevidéu, lançando uma onda de manifestações que percorreu a rede postal, organizada por Carrión, mas também por Geoffrey Cook e Julien Blaine chamada The Padín/ Caraballo Project 6 . Esses protestos em ajuda a Padin e Caraballo, dois importantes articulares da arte postal, ganharam a capa da $5^{a}$ edição de Fevereiro de 1978: "Padin and Caraballo are in Jail" Ask for more informations. Transit it. Ulises Carrión".

ao seu criador. Todos os participantes de um projeto pessoal o transformaram em uma obra coletiva”. Catálogo de Ulises Carrión copilado pelo Museu Reina Sofia e publicado em 2016, Dear reader. D’ont read. com textos de Guy Schraenen, Felipe Ehrenberg, João Fernandes, Heriberto Yépez, Javier Maderuelo, Maike Aden.

4 Resumo de Dária Jaremtchuk para o CBHA de 2013 Disponível em: http://www.cbha.art.br/coloquios/2013/ anais/resumos/pdf_comunicadores/daria_jaremtchuk.pdf. Acessado em 28/09/2020

5 De acordo com Camnitzer, em seu livro Conceptualism in Latin American Art: Didactics of Liberation, dá a entender que Padin e Caraballo ficaram presos até por volta de 1981 (2007, p. 77).

6 Lomholt Archive. Disponível em: https://www.lomholtmailartarchive.dk/mail-art-network/1978-06-07-ogaz; https://www.lomholtmailartarchive.dk/mail-art-network/1978-09-00-blaine. Acessados em 28/09/2020. 
A partir de um recorte de gênero dos doze números circulados entre Janeiro de 1977 e Outubro de 1978, participaram artistas como Paulo Bruscky, Klaus Groh, Antonio Vigo, Guy Schraenen, G.J de Rook, todos esses articuladores dessa rede. Além, artistas como Richard Prince, Gábor Tóth, Endre Tót, Cavellini, Karel Miller e J. Medeiros, também figuras constantes nesses espaços de circulação postal.

Entre os postais, estampas e fotografias enviadas se encontram os seguintes trabalhos: "In complete control" (Richard Prince, setembro de 1977 ), "a little extension of the art"- i'm my first idea; you're the second (Gábor Tóth, setembro de 1977), "Poem limited to sixty lines" (Paulo Bruscky, setembro de 1977), Zeropost (Endre Tót, Outubro de 1977), "Artistical Solidarity for 1974" ( G.J de Rook, janeiro de 1978), "Closer to clouds" (Karel Miller, janeiro de 1978), "sorry not art today "(Gábor Tóth, abril de 1978),"pornartsucks” (Aart van Barneveld, junho de 1978).

Ao nos atentarmos para os títulos desses trabalhos, em relação aos artistas homens, questões como política, imaginário pornográfico, individualismo mas também comunicação, desconstrução dos parâmetros e subversão são alguns dos traços que atravessam essas produções. Dito isso, quais tipos de trabalhos eram enviados pelas mulheres artistas que circulavam por essa mesma rede e ao longo da revista Ephemera?

Ao analisarmos o corpo dos 12 volumes o número de mulheres artistas participantes não são longos e se dividem em artistas do Leste da Europa e Cone Sul, mas também Estados Unidos. Essa presença situada é significativa das áreas de circulação dessa publicação e nos indica quais tipos de diálogo o espaço editorial alcançava. A rede de arte postal, em suas constelações, teve forte presença nos Estados Unidos, na Alemanha, no Brasil, na Argentina, no Uruguai, assim como nos países do Leste, de modo amplo. Esse mapeamento nos permite entender porque foram essas e não outras artistas a publicarem seus trabalhos. Mas o que essas artistas, enquanto mulheres, pretendiam evidenciar nesses trabalhos?

\section{Participações e críticas ativas, por elas}

Na capa da primeira edição, de novembro de 1977, encontramos poemas visuais e textos das artistas norte-americanas Judith Hoffmann, "Art Spoken Here", Los Angeles (1977) e Dorothy lannone "Ich leibe dich weil du mühelos nie in klischees redest" ("Eu te amo porque você nunca usa clichês sem cansaço") - sem local e sem data. Ambas as artistas pensavam aspectos do feminino, sendo ativistas seja da causa artística no caso de Judith Hoofman - e aqui podemos pensar uma aproximação com o coletivo Art Workers Coalition, Nova York (1969-1971) - e das sexualidades femininas com Dorothy lannone. Ainda uma terceira mulher artista aparece, a artista experimental holandesa Silvia Steiger com Corps de Garde, Graningen, 1976 “Muschel Kiefernzapfen Mutter” ("concha, noz, mãe"). Outro trabalho que segue essa mesma linha e publicado na edição de setembro de 1977, é o texto da colecionadora Ellen Sragow "Das museum der fragen” (O museu das questões), questionando os limites impostos à informação e a importância da crítica para a autonomia social, em abril de 1978 "under scrutiny", still do video Vital Statistics of a Citizen, Simply Obtained (1977) de Martha Rosler, enviado por Leucadia, da Califórnia e na na oitava edição de maio de 1978, a 
canadense Anna Banana, com a chamada Banana Post da Banana Productions e a revista Vile ${ }^{7}$

Pequenos poemas e textos como esses apresentam uma visão crítica por parte dessas artistas em relação às instituições, exploram a arte como liberdade de expressão mas também nos mostram rastros de questões afetivas, "eu te amo porque você nunca usa clichês sem cansaço", e ainda uma genealogia da construção da representação do feminino através de elementos como "concha, noz e mãe", em Silvia Steiger, ou dos aparatos de poder e controle sobre os corpos femininos com a reapropriação por Leucadia de trabalho de Martha Rosler.

É importante frisar que a maioria desses trabalhos eram pequenos envios, para diminuir os custos das postagens e para facilitar a disseminação. Em muitos casos, como o das artistas acima ou dos artistas homens no tópico anterior, eram enviadas estampas postais e pequenas frases escritas à mão e ainda cópias fotográficas ou xerox, o que torna esses trabalhos sem valor de mercado.

Por outro lado, essas trocas postais foram capazes de agenciar espaços de diálogo. Essa é uma questão fundamental, já que ao analisarmos as expografias dessas e de outras artistas que circulam pela rede postal nesse momento, essas chamadas não constam em seus currículos, com exceções como a artista e professora Carmela Gross, fazendo com que essas publicações, que já naquele momento circulavam por um esquema alternativo, se tornem nas análises contemporâneas da história da arte ainda mais esquecidas e/ ou marginalizadas, em detrimento das dinâmicas de mercado, sistemas curatoriais e demais demandas de exposição e visibilidade mas que, naquele momento, constituíam um canal centrado nas experimentações, trocas e informações mais do que de visibilidade. Ou seja, o foco era a comunicação.

Voltando às publicações de mulheres artistas presentes na revista Ephemera, participam importantes artistas do Leste da Europa como Katalin Ladik, Dóra Maurer, Helena Kontova e Urszula Petasz. Não é acaso que as publicações dessas artistas se encontram acompanhadas por seus companheiros, grupos de artistas ou como objetos e bastidores para outros artistas como Katalin Ladik e Urszula Petasz.

Helena Kontova, companheira de Giancarlo Politi, têm registro de seu casamento publicado na terceira edição, de janeiro de 1978, fotografada pelo artista húngaro e amigo do casal, Gabor Attalai. Helena Kontova foi a responsável por uma importante aproximação da revista italiana Flash Art, de Polliti, com a cena artística experimental do Leste da Europa, implementando também a seção de entrevistas com artistas (KEMP-WELCH, 2018). Hoje, em conjunto com Polliti, é também diretora e co-fundadora da Bienal de Praga. A revista Flash Art (ainda em fluxo), assim como a norte-americana Avalanche (1970-1976) de Liza Béar e Willoughby Sharp foi uma das mais importantes revistas sobre arte experimental em circulação no momento.

Nessa mesma edição de 1978, os trabalhos de capa são das artistas Urszula Petasz "Pawel Petasz against a background of art" e Katalin Ladik com János Kass "Head", ambos de

7 É importante pontuar que Anna Banana, assim como Angelika Schmidt foram articuladoras fundamentais para a produção de debates de gênero na arte postal, criando chamadas como Fe'male Art, de 1978, divulgada pela revista Vile. 
1977, produzidos em Elglag na Polônia e em Budapeste. A figura de Urszula Petasz, fotógrafa e companheira de Pawel Petasz, nos é completamente desconhecida, assim como a maioria das outras artistas citadas acima. Urszula atuava nos bastidores, às vezes registrando seu companheiro em situações de reflexão artística. Ela não possui expografia, sendo esse registro enviado à Ephemera e algumas correspondências no arquivo de arte postal Lomholt Archive, as poucas evidências de sua presença nesse circuito.

Já, por outro lado, Katalin Ladik uma das principais artistas da cena húngara, que possui nomes importantes no campo de mulheres artistas como Dóra Maurer, Judit Kele, Orshi Drozdik, Ilona Keserü Ilona e El Kazovsky, aparece com János Kass, performando “Head” (1977). Nesse registro Katalin Ladik (figura 2) aparece segurando em frente a seu rosto uma moldura, cujo enquadramento é ajustado pelo artista e o plano de fundo se constitui de cartazes e trabalhos do ilustrador, em que aparecem um conjunto de rostos e máscaras. A imagem da artista se confunde com essa coleção de outros rostos artificiais que também representam uma certa cultura do feminino, a ação de emoldurar o próprio rosto, nesse contexto, coloca a artista em uma relação entre objeto e fetiche. A artista é transformada pelo ato de János Kass em mais um rosto de sua coleção.

Katalin Ladik, artista muito ativa na cena húngara com suas performances sonoras e programa na rádio Novi Sad, ao longo das décadas de 1970 e 1980 atua como importante protagonista nas desconstruções dos estereótipos de gênero, utilizando de seu espaço nas mídias e de seu próprio corpo como espaço de crítica (KÜRTI, 2017). Nesse sentido os trabalhos mais conhecidos da artista são as constantes mutações faciais em peças teatrais ou registros fotográficos desfigurando seu rosto prensando-o sob uma chapa de vidro transparente, em trabalhos como Poemin (1978-2016), Blackshave Poem (1978) e Poemask (1982-2018). Nessa interação com Janós Kass, ela se permite a subordinação com a finalidade de problematizar as questões de objetificação da mulher.

Outra artista importante da cena húngara a participar da revista Ephemera é Dóra Maurer, na edição especial Hungria, de setembro de 1978. O trabalho publicado é o registro fotográfico realizado por Dóra de seus amigos e companheiros artistas no jardim da Chapel Studio, espaço artístico experimental de György Galántai, fechado pelas autoridades locais em 19738 (MAURER; GÁYOR, 2002). Essa fotografia ficou bastante conhecida pelo circuito experimental, sendo utilizada inúmeras vezes para ilustrar as aproximações entre os artistas daquela cena. Nesse registro, Dóra Maurer inicia algumas das questões fotográficas que seriam essenciais em sua poética ao longo da década de 1970, pensando o diálogo entre os fragmentos e os ângulos na fotografia. Apesar de na revista Ephemera aparecer o nome da artista, sua imagem e presença só acontecem através do registro fotográfico, também nos bastidores, aquela que capta o momento de outros, assim como Urszula Petasz.

8 Essa imagem pode ser consultada pelo site Artsy. Disponível em: https://www.artsy.net/artwork/doramaurer-spatial-confusion-miklos-erdely-tibor-gayor-gyorgy-jovanovics-tamas-szentj-by. Acessado em: 28/09/2020 


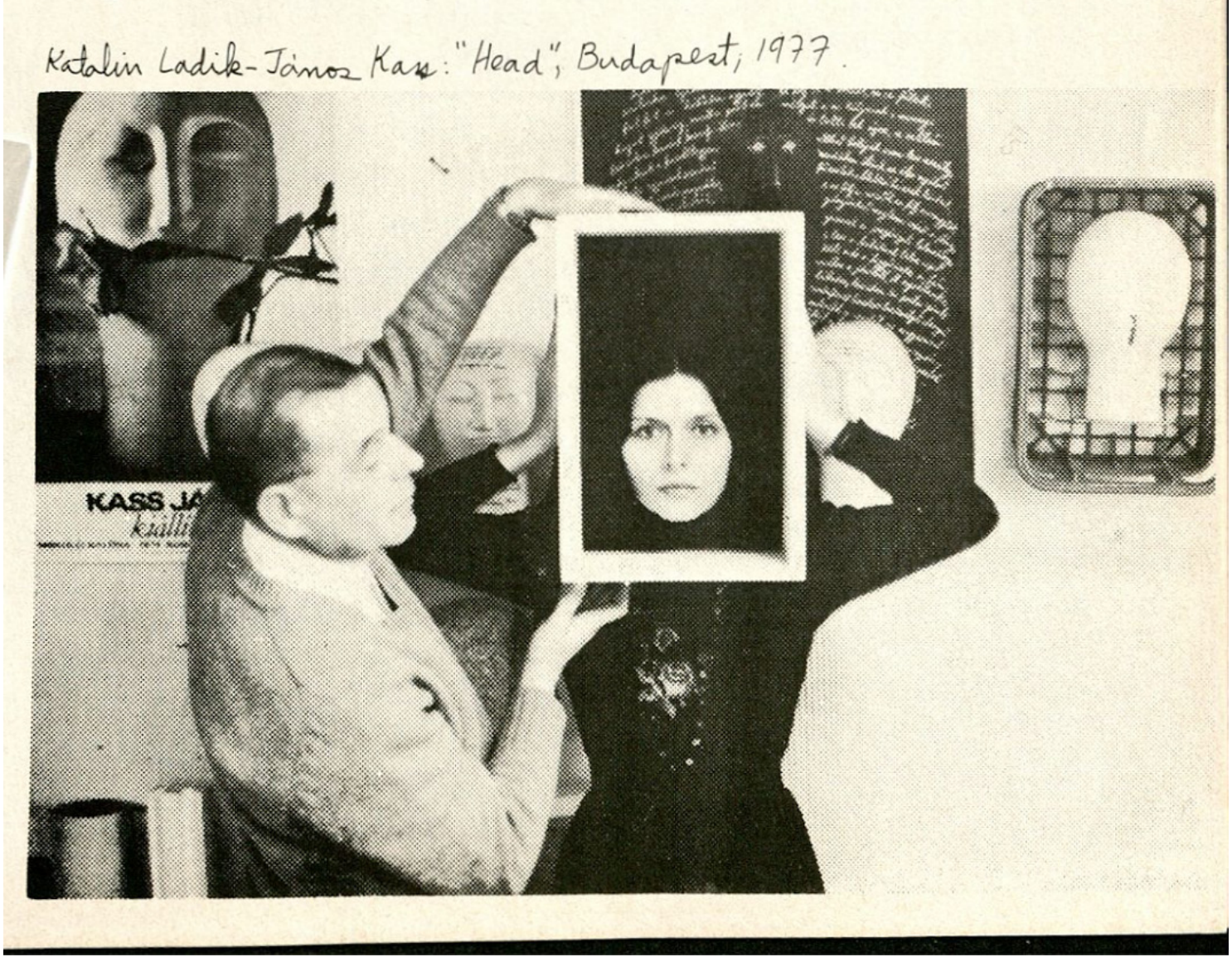

Figura 2. - Katalin Ladik e Janós Kass, Head, 1977, Fotografia, publicado na revista Ephemera n 3, em janeiro de 1978. Fonte: Monoskop.

Dóra, assim como Katalin Ladik, foi outra artista importante na cena do Leste, articulando exposições através de suas revistas SUMUS e seu projeto Ma-Ma, realizados com Tibór Gáyor e László Beke, além do ateliê de criatividade Creativity Exercises - Fantasy Developing Exercises (FAFEJ) com Miklos Erdély, figura central da cena experimental húngara, no Ganz Mávag Cultural Center em Budapeste.

Em relação aos trabalhos de mulheres artistas do Cone Sul o enfoque se volta mais às questões da linguagem, das origens e dos espaços públicos, atravessando também questões políticas, afetivas e de gênero que já circulavam por outras publicações e copilações via rede postal. Entre essas artistas estão Regina Silveira, Vera Chaves Barcellos, Neide de Sá e Graciela Marx.

Regina Silveira aparece em três publicações, a de número 2 de 1977, a de número 9 de 1978 junto com o coletivo Nervo Óptico (Vera Chaves Barcellos e Mara Álvares) e a de número 12 , edição Brasil, na qual aparecem Vera Chaves Barcellos com o trabalho fotográfico Traços do homem de 1974 e o poema visual Tabu 7 de Neide Sá. Para essas edições Regina Silveira apresenta a série 
Brazil Today, que circula em várias edições postais como Kunst per Post de 1976, organizada por Gj de Rook e From Bookworks to Mailworks (figura 10) em 1978, por Carrión.

Em Brazil Today (figura 3 e 4), Regina Silveira utiliza a apropriação de postais, inserindo elementos serigráficos sobre eles (figura 8). Essa série de 1977 é composta por diferentes eixos Brazilian Birds, Indians from Brazil, The Cities e Natural Beauties. É essa última série Natural Beauties que a artista escolhe para circulação. Nesses postais aparecem monumentos da cidade de São Paulo, a estátua de Brecheret, Monumento às Bandeiras, de 1953, em frente ao Parque no Ibirapuera, uma das estações de metrô, Jabaquara, com foco na modernidade do transporte público em São Paulo, o Museu do Ipiranga, o MASP, o Viaduto do Chá e o Palácio do Itamaraty em Brasília, projetado por Niemeyer. Nesses trabalhos Regina Silveira interfere adicionando carros abarrotados e amassados e cenas de um aterro sanitário em frente ao Museu do Ipiranga. Essas contradições entre os monumentos, símbolos da modernidade arquitetônica e econômica de cidades como São Paulo e Brasília entram em descompasso frente a outros acúmulos urbanos, dos ferros velhos e aterros, marcando uma sociedade em incessante consumo, apresentando uma outra faceta da modernização.

Outros trabalhos como o do grupo Nervo Óptico, dialogam com a identidade nacional, os retirantes, a cultura caipira e do interior e ressignificações de monumentos nacionais com uma verve crítica (figura 5). Nesse momento, sobretudo para as artistas que permaneceram no país, algumas estratégias se desenrolaram em torno das publicações independentes com revistas como Nervo Óptico, de grupo de mesmo nome, da qual participavam as artistas do Rio Grande do Sul, Vera Chaves Barcellos, Mara Álvares e Romanita Disconzi e a Revista Ponto, idealizada pelo grupo Poema Processo (Rio de Janeiro - Natal) - movimento do qual participaram ao longo de sua duração mais de 70 artistas incluindo Clemente Padin e Antonio Vigo (NÓBREGA, 2017, p. 9) - cujos fundadores foram Neide de Sá, em conjunto com Wlademir Dias-Pino, Álvaro de Sá, Moacy Cirne, Falves Silva, Frederico Marcos, Dailor Varela e Joaquim Branco (NÓBREGA, 2017).

A revista Ponto e a publicação impressa do grupo Nervo Óptico tiveram pouca duração, Nervo Óptico teve publicações mensais, chegando a 13 números entre 1977 e $1978^{9}$, circulando na mesma época que a revista Ephemera, e a Ponto, com duas edições, Ponto 1 de 1967 e Ponto 2 de 1968, além da edição conjunta com a revista editada por Clemente Padin, Ovum 10. Essas publicações levantaram debates acerca da produção artística do período e sua relação com uma certa militância visual (FAVARETTO, $2018^{10}$ ), mas também através dos trabalhos publicados, em especial o das artistas Vera Chaves, Mara Álvares e Neide Sá, que problematizam a representação e reprodução da imagem feminina divulgada pelos meios de comunicação.

Em Traços do homem (1974) de Vera Chaves (figura 6), publicada no número 12, edição

9 Dados extraídos da Galeria Superfície. Disponível em: http://www.galeriasuperficie.com.br/artistas/gruponervo-optico/. Acessado em 28/09/2020.

10 Texto do professor Celso Favaretto para a revista Modos v.1 n.3, 2017: A contracultura, entre a curtição e o experimental. Disponível em: https://www.publionline.iar.unicamp.br/index.php/mod/article/view/872. Acessado em 28/09/2020. 
Brasil, a fotografia se assemelha ao registro de raízes ou areia, após a chuva, pela sua sinuosidade, marcando os percursos da civilização na natureza, caminhos, trajetórias, indícios de passagem. Neide de Sá, em seu Tabu 7 (figura 7), desconstrói o interdito, um tabu do qual não nos é possível a apreensão reflexiva. São letras soltas e engarrafadas que são despejadas em um boca que as engole. Algumas letras são evidentes, E’s, M, U, J, Y, em caixa alta. A boca devora o tabu, esvaziando aos poucos, seu conteúdo.

Os trabalhos de Nervo Óptico e Graciela Marx que aparecem na edição de $n^{\circ} 9$ da Ephemera dialogam com determinadas questões de classe e gênero. Em Sociedade Anônima (figura 5) Mara Álvares e Vera Chaves Barcellos aparecem ambas representando mulheres em situação de pobreza, em temas como migração e cultura do campo. Nesse momento de final da década de 1960 se dava a formação do projeto da reforma agrária brasileira, solapado pelo regime militar, de modo que o trabalho do grupo Nervo Óptico vêm também expor essa questão.

Já, Graciela Marx (figura 8), uma presença central nas articulações da cena postal da região da Prata, apresenta uma versão do silenciamento da cultura ao feminino, apresentando a imagem de uma mulher parcialmente nua, amarrada a uma cadeira. Acima em um balão a imagem de duas figuras que se assemelham a cupidos, dentro de um coração, com asas de morcego. As facetas de poder do campo amoroso: desejo e violência, controle e dominação.

Em relação a esses trabalhos poderíamos pensar algumas questões acerca de suas intencionalidades. Se a participação na rede de arte postal era livre, e sua proposta se configurava na ausência de curadoria, a favor do livre acesso e publicação - aos moldes das edições da Jovem Arte Contemporânea, a partir de sua quarta edição, realizadas no Museu de Arte Contemporânea de São Paulo (MAC-USP) (PALADINO, 201511) na qual inclusive, circulavam essas e esses mesmos artistas da rede postal - porque foram exatamente esses os trabalhos escolhidos por essas artistas para circulação? Quais tipos de diálogos e embates elas pretendiam levantar?

Temáticas como espaço público, espaço privado, discursos e regimes de visibilidade atravessam esses envios. Nesse sentido, as intencionalidades não eram unicamente voltadas à construção crítica e a transgressão de padrões e normas sociais, políticas e das representações visuais em torno da mulher e do feminino, mas uma crítica ampliada, e partilhada entre muitos desses artistas, às relações de poder, em suas múltiplas esferas.

Se ao longo dos números da revista Ephemera essas foram as únicas mulheres artistas a publicarem e esses os únicos trabalhos circulados, outras artistas dessas regiões como Carmela Gross, Amelia Toledo, Letícia Parente, Anna Bella Geiger, Liliana Porter, Lea Lublin, Sanja Ivekovic, Ewa Partum, para citar apenas algumas, integram os nomes de artistas que participam ativamente da rede postal, dialogando nas mesmas chaves que as demais artistas aqui citadas: entre os embates de gênero, o campo da subjetividade e da autobiografia e a crítica social e política, muitas vezes interligadas em único trabalho.

11 Dissertação de Luiza Mader Paladino: Conceitualismos em trânsito: intercâmbios artísticos entre Brasil e Argentina na década de 1970 - MAC USPe CAYC. Disponível em:https://teses.usp.br/teses/disponiveis/93/93131/ tde-27012016-132242/pt-br.php. Acessado em: 28/09/2020 
Ao analisarmos o circuito de arte postal, em relação à esfera institucional do período, que no Brasil se encontrava nesse momento em formação e eram centralizados em algumas poucas instituições interessadas em arte contemporânea, como o MAC-USP e o MAM-RJ, faz-se substancial essa presença de mulheres artistas, mesmo que elas ainda se encontrem em menor número.

Em relação às práticas institucionalizadas do sistema das artes, esses trabalhos circulados pela rede postal ocupam muitas vezes os espaços de arquivo, sendo colocados como uma categoria cujo valor expositivo tem menor valia. Mas, suas propostas de comunicação, com certas rachaduras do sistema e produção à margem, foram capazes de ativar diálogos criativos, experimentais, fomentar propostas efêmeras e fora do radar, marcando um importante momento da produção artística, retomando à arte como processo de pensamento, liberdade e crítica social, como saída e fuga aos tempos de violência e opressão dessas décadas. Se em meados da década de 1980 suas movimentações diminuíram, seus vestígios e memórias nesses acervos nos permitem analisar os interesses, os olhares e mesmo as passagens pela trajetória da constituição dos circuitos de arte, mas também dos trajetos dessas e desses artistas em suas próprias poéticas.

Portanto, resgatar e preencher essas lacunas se torna fundamental para a permanente percepção dos discursos, dos controles e das relações de poder e esquecimento orquestrados no sistema das artes, assim como nos permite evidenciar as dinâmicas de inserção e deslocamento que fazem parte das práticas institucionais, revelando presenças por vezes camufladas ou ausentes nos discursos da história.

\section{Conclusão}

Como vimos, a participação dessas mulheres artistas na revista Ephemera, mas também na rede postal, em copilações citadas como From Bookworks to Mailworks, trazem contribuições importantes em termos críticos para se pensar questões políticas, de gênero e linguísticas que percorrem os debates artísticos das décadas de 1970 e 1980. Em termos de produção e publicação independe essas mulheres artistas não somente participaram ativamente de chamadas como também gestaram seus próprios trabalhos como a revista MaMaBLAnCa de Graciela Marx em dois números, 1980, Los codices marginales de MaMaBLAnCa e em 1982, MaMaBLAnCa Treasures. Circularam também pela rede postal trabalhos solos e portifólios, divulgados através do boletim Info (International Artists' Cooperation) de Klaus Groh, além de chamadas de eventos realizados por elas, como a Mostra Internacional de Arte Postal realizada em 1981 no Espaço N.O de Ana Torrano, Vera Chaves Barcellos, Karin Lambretch e outras, em Porto Alegre.

(na página seguinte)

Figura 3. - Regina Silveira, Brazil Today, 1977, Serigrafia sobre postal, 10x15, publicado na revista Ephemera n 2, em dezembro de 1977. Fonte: Monoskop

Figura 4. - Regina Silveira, Proporção para um monumento, 1973, Serigrafia, publicado na revista Ephemera n 12, de outubro de 1978 Fonte: Monoskop. 
"Brazil today", Regina Silveira, Saõ Paulo, 1977
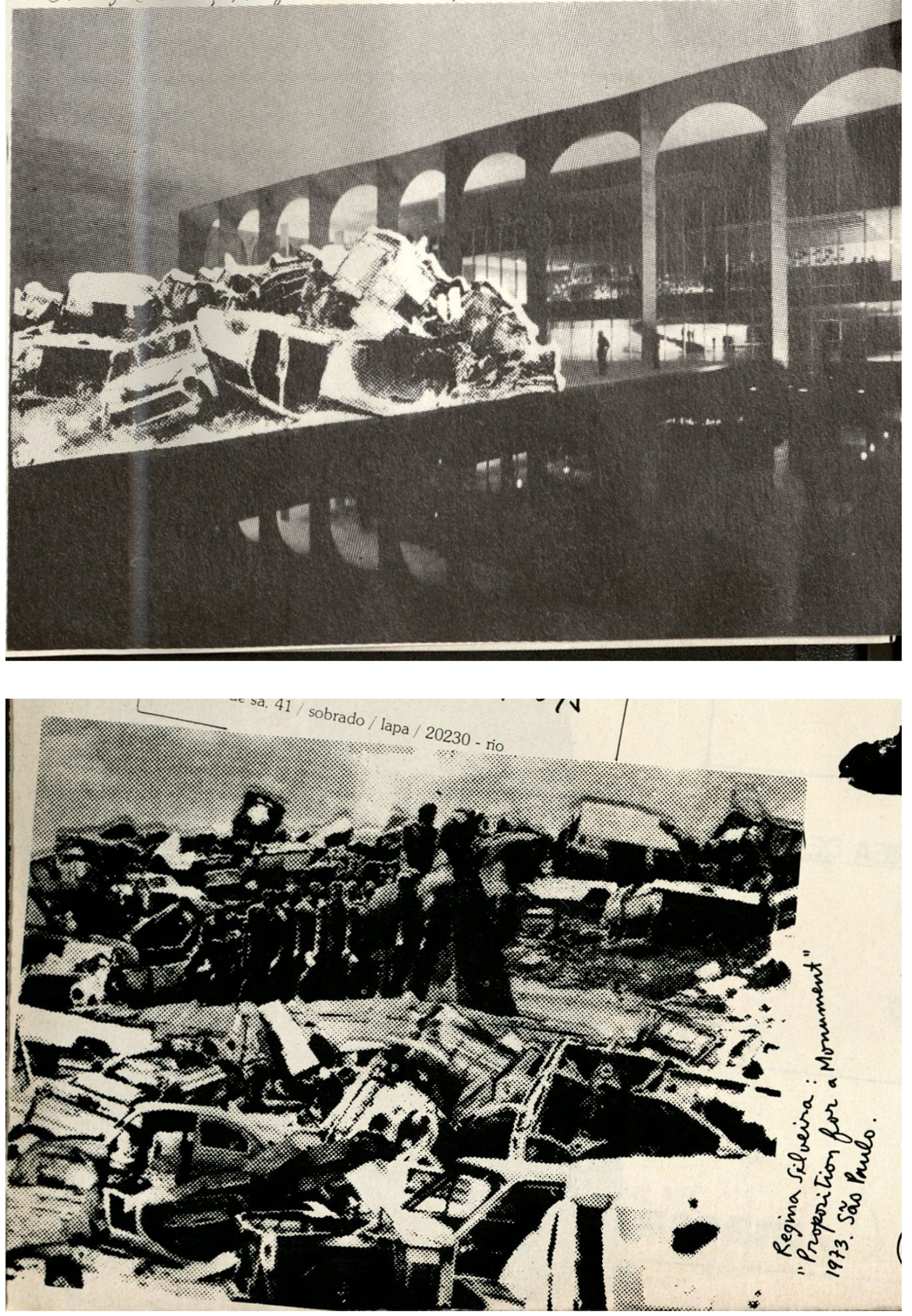


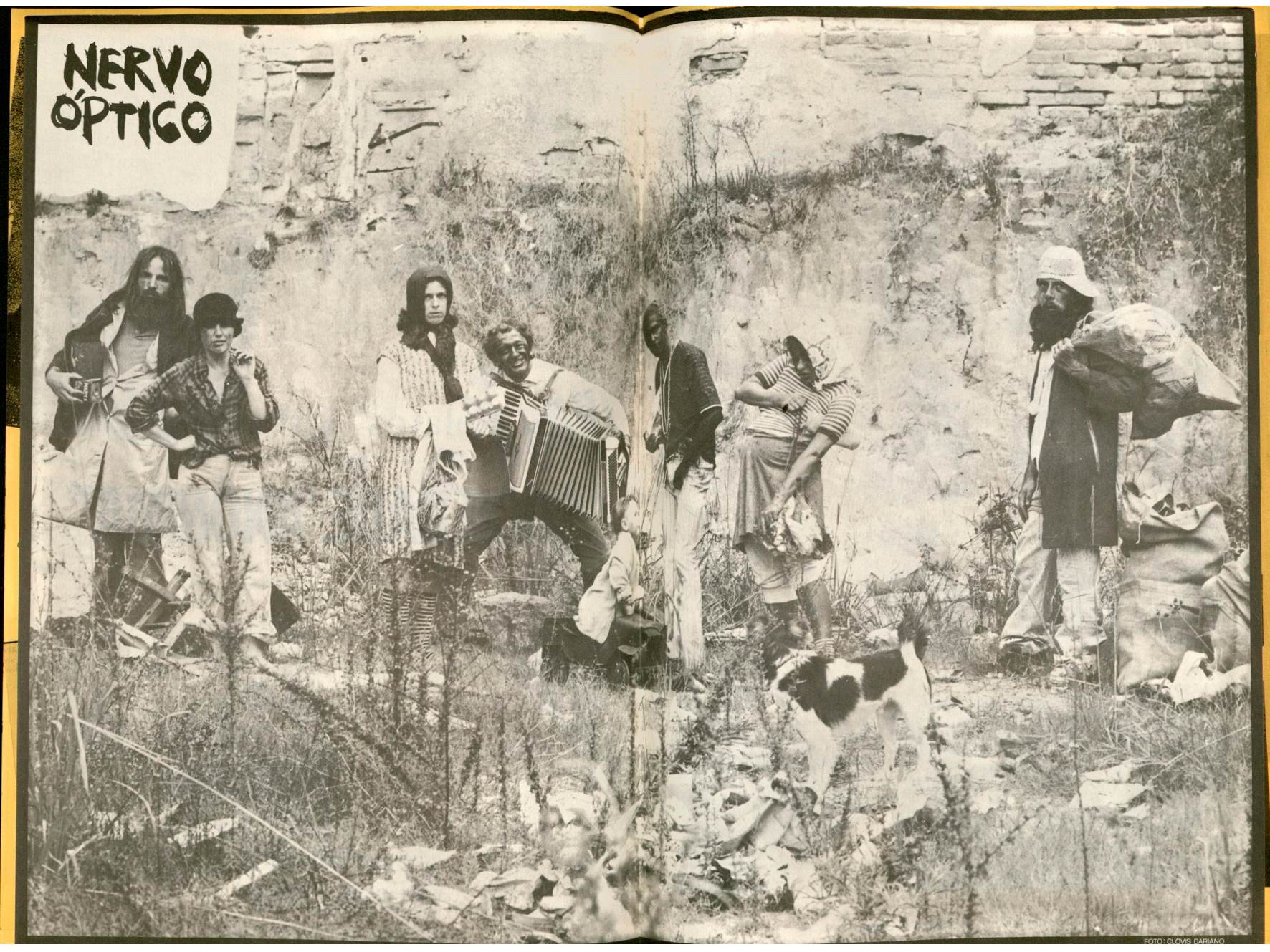

Figura 5. - Coletivo Nervo Óptico (cópia original), Sociedade Anônima, Fotografia, publicado na revista Ephemera n 9, de julho de 1978 Fonte: Monoskop. 


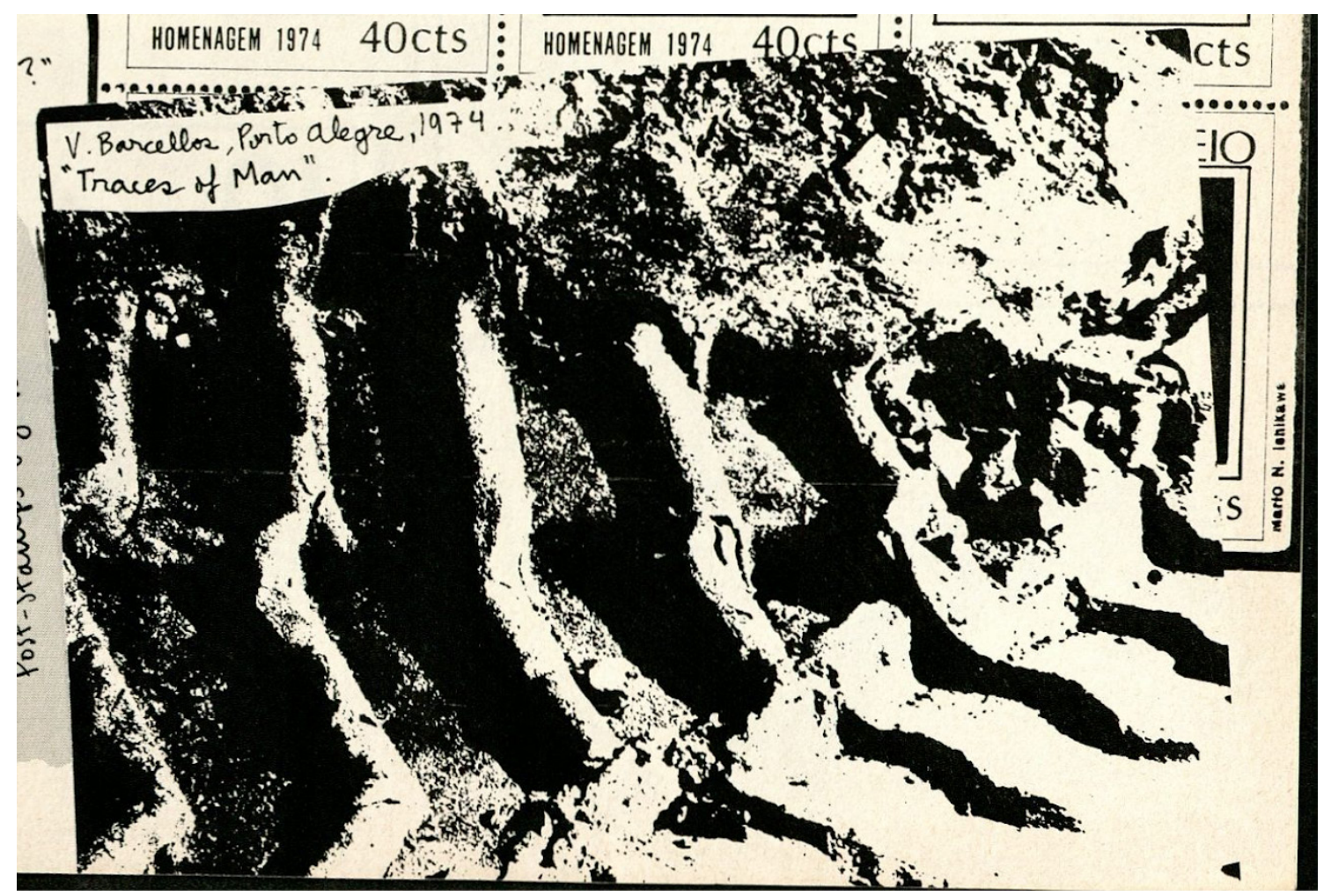

Figura 6. - Vera Chaves Barcellos, Traços do Homem, 1974, fotografia, publicado na revista Ephemera n 12, de outubro de 1978 Fonte: Monoskop 


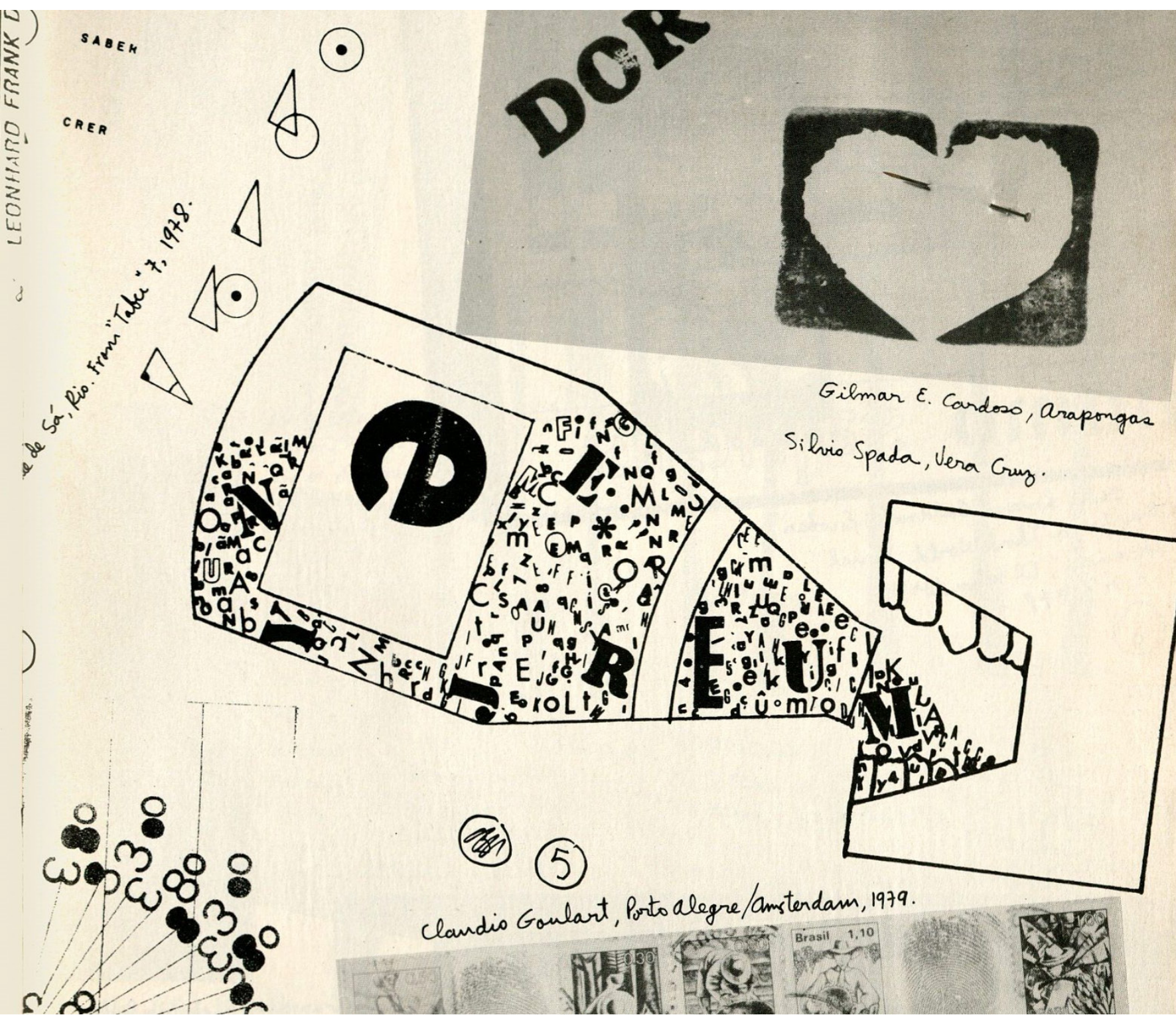

Figura 7. - Neide de Sá, Tabu 7, poesia visual, publicado na revista Ephemera n 12, de outubro de 1978 Fonte: Monoskop. 


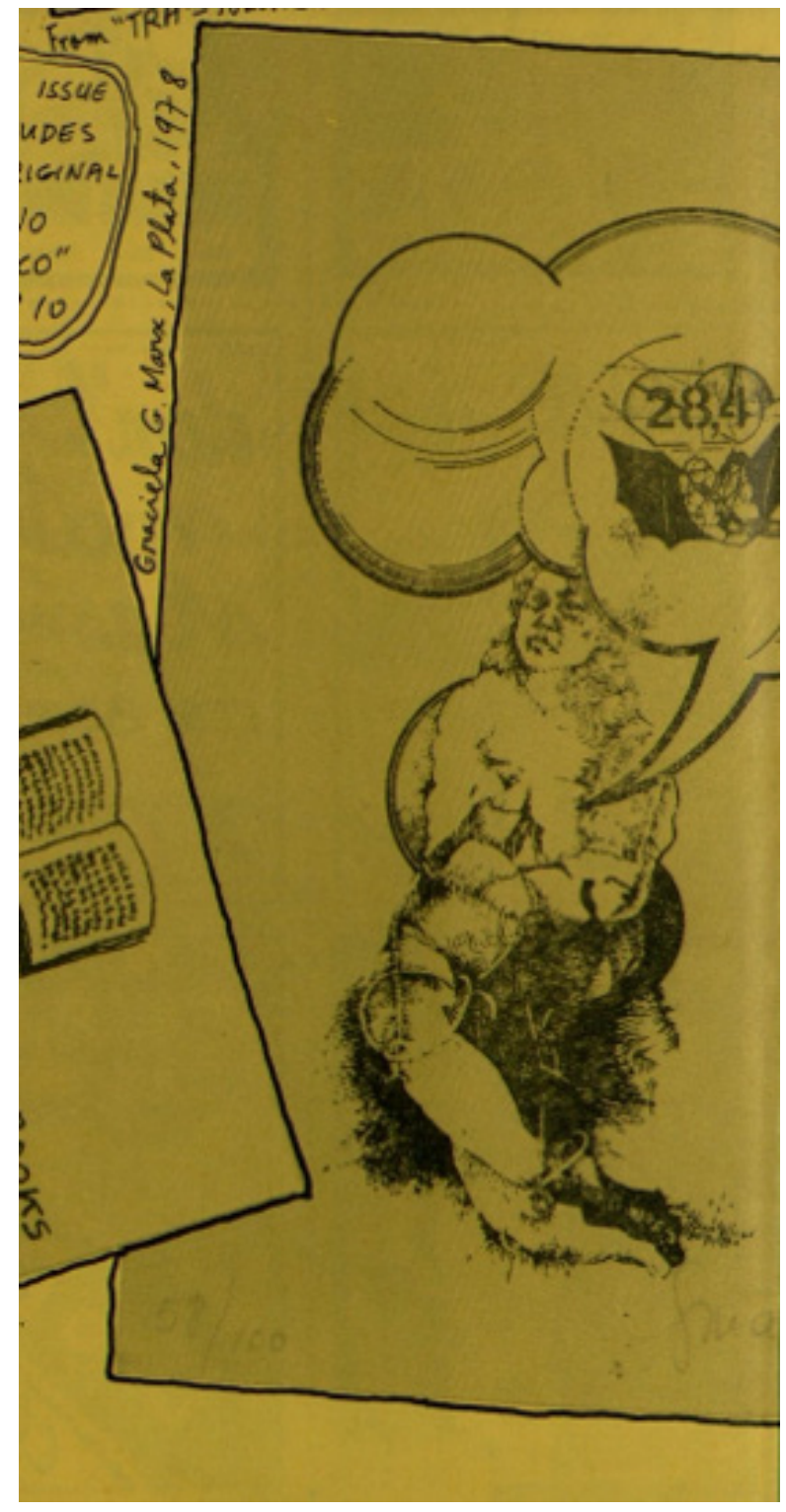

Figura 8. - Graciela Marx, sem título, desenho, publicado na revista Ephemera n 9, de julho de 1978 Fonte: Monoskop. 

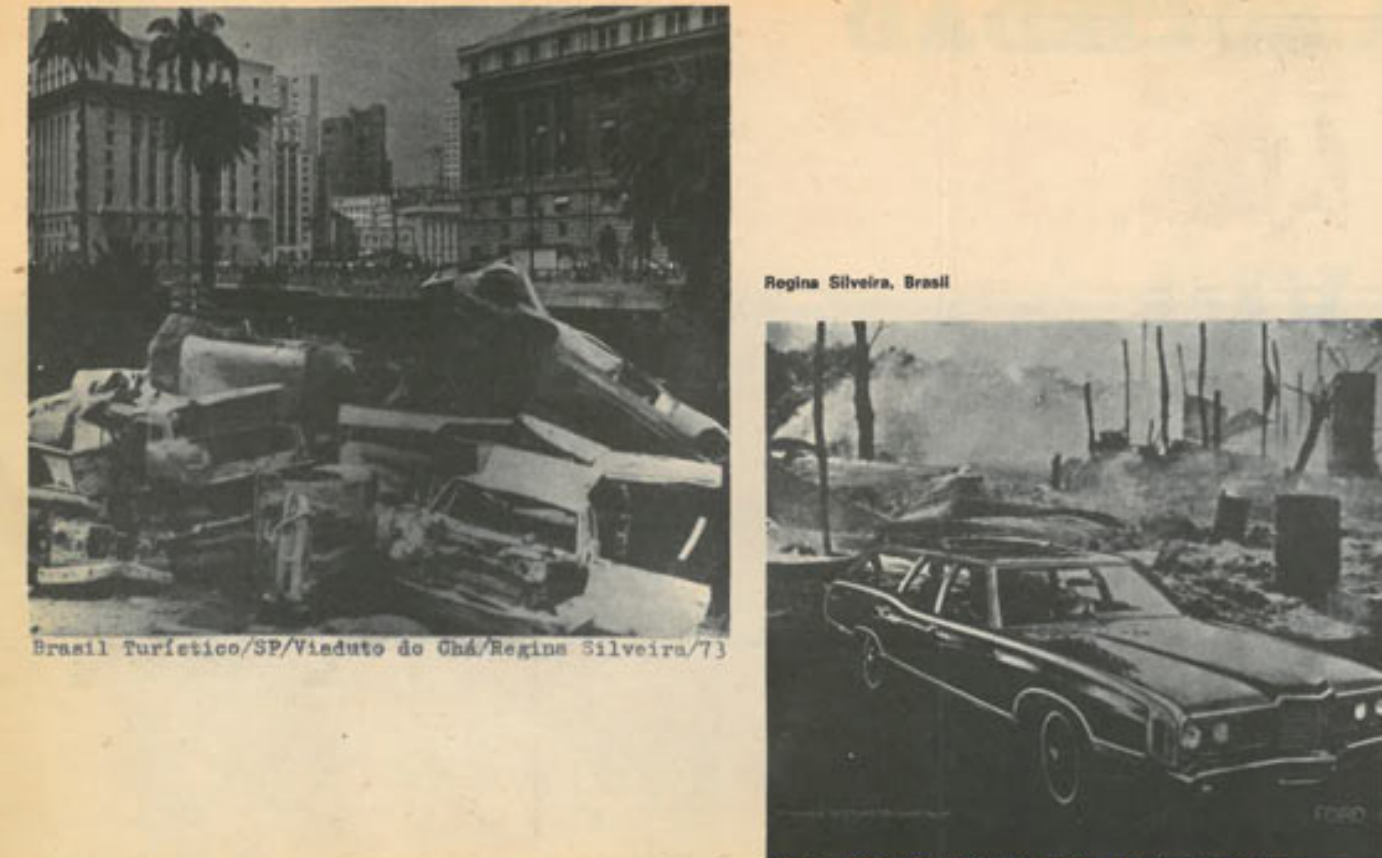

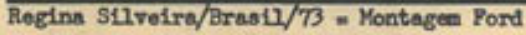

La mayoria de los artistas en Latinoamérica producen desde las grandes urbes, desde los grandes centros. Los poderosos y sus decisiones, los problemas inherentes a nuestra desenfrenada sociedad de consumo, el desorden que resulta de la ausencia de planlficación urbana, los atentados en contra de los ciclos ecológicos, son condicionantes que afectan al artista al igual que a todo cludadano. Una vez más, las tócnicas nuevas a las que recurre el creador para expresar sus preocupaciones parecen ser las más idóneas, aunque lo que produzcan no sea 'bello': reflejan la enajenación en las urbes, el producto visual es la visual de la ciudad.... en el escueto blanco y negro de la fotocopia, en la fidelidad - manipulable - de la fotografia, en el reprocesamiento de imágenes publicitarias y 'encontradas' en peribdicos y revistas.

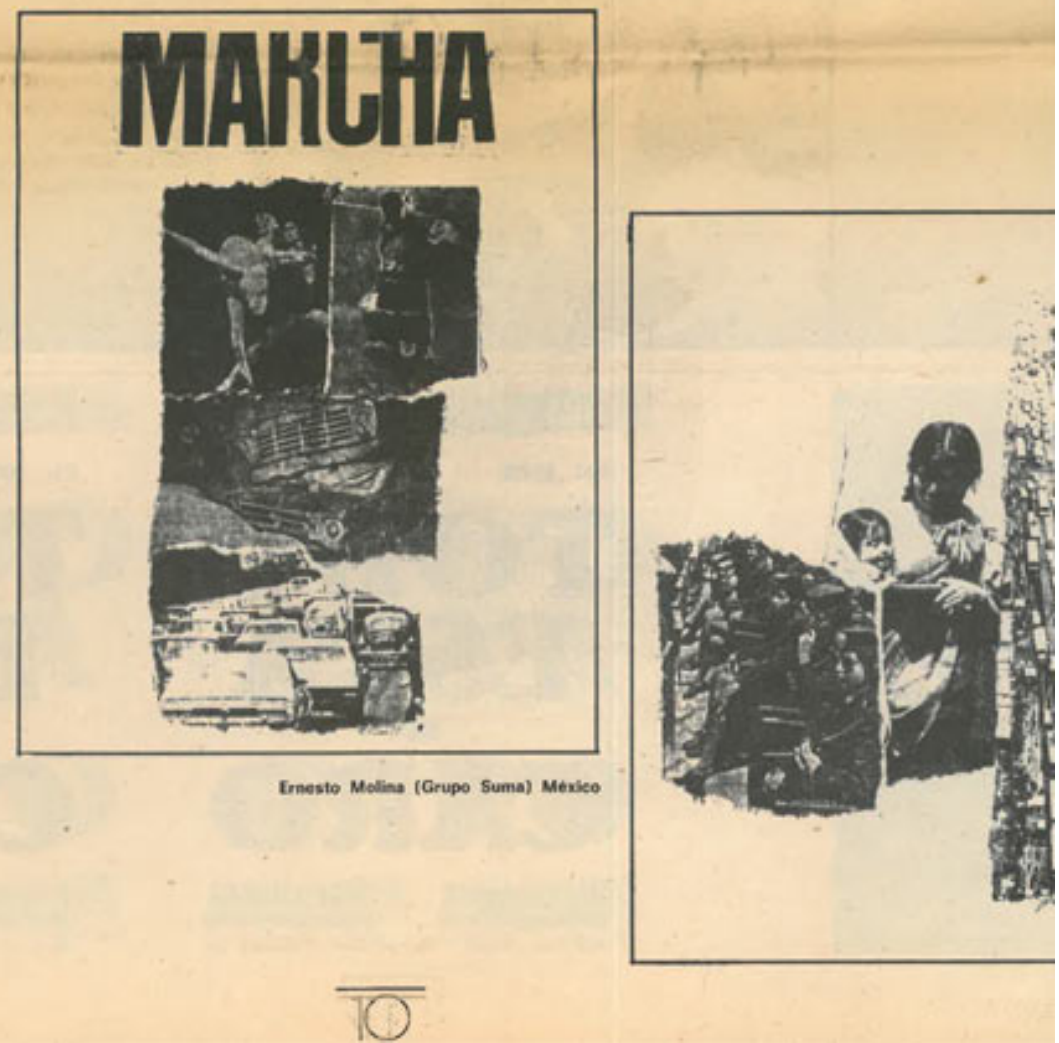

Figura 9. - Felipe Ehrenberg, Testimonios de Latinoamérica, in: La semana de bellas artes, No. 42, Instituto Nacional De Bellas Artes-Direccion De Literatura, Mexico, 1978 Fonte: Artpool https://www.artpool.hu/ 


\section{Van kunstenaarsboeken}

\section{tot postkunst}

Zoals de naam al aangeeft, gaat het in deze tentoonstelling om de raakvlakken, de overeenkomsten, tussen kunstenaarsboeken en postkunst. Beide vormen behoren tot dezelfde periode (min of meer de laatste twee decennia) en beinvioeden en verrijken elkaar. Hoewel het niet mogelijk is een historische lijn te ontdekken die van de ene vorm naar de andere leidt, wil ik toch aantonen dat de postkunst bepaalde tendenties verscherpt heeft in de ontwikkeling van de kunst, die de kunstenaarsboeken reeds op gang gebracht hadden. Deze verscherping heeft belangrijke vormbepalende gevolgen gehad - vandaar dat de titel ook de ontwikkeling van het ene genre naar het andere veronderstelt. (Kunstenaaarsboeken zijn boeken opgevat als uitdrukkingsgeheel, d.w.z., boeken waarin de boodschap bestaat uit de som van alle materiële en formele elementen. Postkunst is elk posts-

pastioned

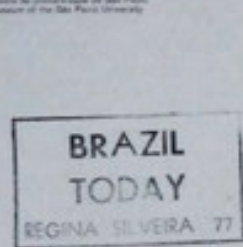

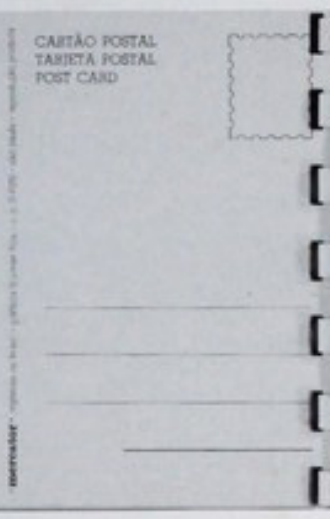

I

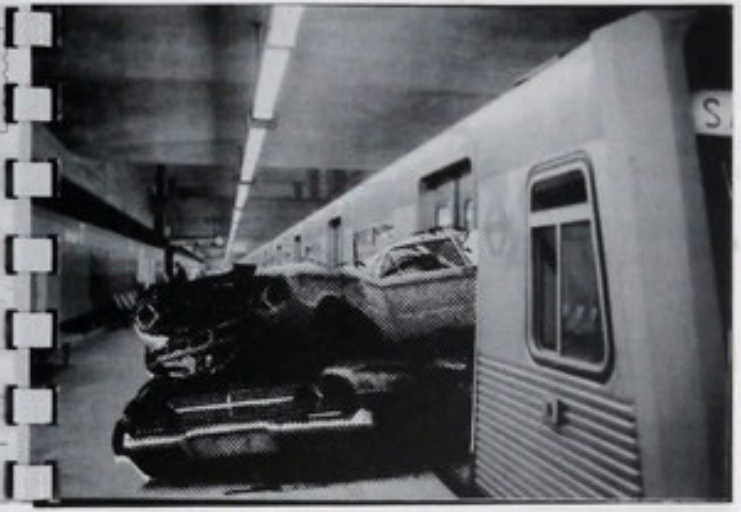

Regina Silveira: Brazil Today

\section{From Bookworks}

\section{to Mailworks}

As the name indicates, this exhibition tries to show the contact points, the relationships, between artists' bookworks and Mail Art. Both forms are contemparary (they belong more or less to the last two decades) and influence and enrich each other. Although it isn't possible to draw a chronological sequence leading from one art form to the other, I want to show, that Mall Art radicalizes some tendencies in the evolution of the art process - evolution that the bookworks had triggered, and that such radicalization has important formal consequences. This is the reason for the title suggesting a development from the one form to the other. (Bookworks are books thar are conceived as an expressive unity, that is to say where the message is the sum of all the material and formal elements. Mallart is any postal sending that incorporates one, several or all $t-$ 


\section{Referências}

CAMNITZER L. Conceptualism in Latin American Art [Didactics of Liberation]. University of Texas Press, 2007.

KÜRTI, E. Screaming Hole [Poetry, Sound and action as intermedia practice in the work of Katalin Ladik]. Budapeste: acb RESEARCHLAB, 2017.

FAVARETTO, C. A contracultura, entre a curtição e o experimental. In: Revista Modos v.1 n.3, 2017. Disponível em: https://www.publionline.iar.unicamp.br/index.php/mod/article/view/872. Acessado em 28/09/2020.

GALÁNTAI, G; KLANICZAY, J. Artpool [The Experimental Art Archive of East-Central Europe]. Budapeste: Artpool, 2013.

JAREMTCHUK, D. Anna Bella Geiger: passagens conceituais, EDUSP, Editora A/C: São Paulo, Belo Horizonte, 2007.

KEMP-WELCH, K. Networking the Bloc [experimental art in Eastern Europe 1965-1981]. Cambridge: Massachusetts Institute of Technology, 2018.

MAURER, D; GÁYOR, T. Parallele Lebenswerke - Párhuzamos élemüvek - parallel oeuvres. Budapeste: Városi Múvészeti Múzeum, 2002.

NÓBREGA, G. Poema Processo [Uma vanguarda semiológica]. São Paulo: Martins Fontes, Galeria Superfície, 2017.

SCHRAENEN, G. A story to remember. In: SCHRAENEN, G. et al. Dear reader. Don't read. Madri: Museo Reina Sofia, 2016, p. 15-27. 


\section{Sobre a autora:}

Andréia Paulina Costa é formada em Ciências Sociais pela UNESP - Marilia. Componente do Grupo de Estudo: Imagem, Fotografia e Cinema de 2008-2011. Mestra em Teoria e História da Arquitetura e do Urbanismo, na linha de Cidade, Arte e Cultura pelo Instituto de Arquitetura e Urbanismo (IAU), USP: São Carlos. Integrou o quadro de mestres do Núcleo de Estudo das Espacialidades Contemporâneas (NEC) de 2013 a 2016. Atualmente é doutoranda do Instituto de Artes da UNICAMP, na linha de História, Teoria e Crítica de Arte, onde desenvolve pesquisa sobre as relações entre corpo, espaço e política em artistas mulheres dos anos 1970. É componente do grupo de pesquisa Vanguarda e Modernidade nas Artes no Brasil e no Exterior (UNICAMP) e pesquisadora do LABimagem: Laboratório de Estudos da Imagem (FAAC - Unesp Bauru).andreia.pcosta@yahoo.com.br

Lattes: http://lattes.cnpq.br/8861685140206681

Orcid: https://orcid.org/oooo-0003-0956-2985

Recebido em: 29-09-2020 / Aprovado em:17-11-2020

\section{Como Citar}

Costa Andréia Paulina. A participação de mulheres artistas na revista Ephemera. Revista Estado da Arte, Uberlândia. v.1,n.2, p. 161-179, jul./dez. 2020. https://doi.org/10.14393/EdA-v1-n2-2020-57555 